\title{
When cure becomes an illness-abuse of addictive prescription medicines
}

\author{
Mihajlo (Michael) Jakovljevic ${ }^{1 *}$, Marija Lazarevic ${ }^{2}$, Milena Jurisevic $^{2}$ and \\ Mirjana R. Jovanovic ${ }^{3,4}$
}

${ }^{1}$ Faculty of Medical Sciences, University of Kragujevac, Kragujevac, Serbia, ${ }^{2}$ Department of Pharmacy, Faculty of Medical Sciences, University of Kragujevac, Kragujevac, Serbia, ${ }^{3}$ Department of Psychiatry, Faculty of Medical Sciences, University of Kragujevac, Kragujevac, Serbia, ${ }^{4}$ Psychiatry Clinic, University Clinical Center Kragujevac, Kragujevac, Serbia

Keywords: addiction, drugs of abuse, pharmaceutical market, expenditure, trend, costs

\section{Substance Addiction as Societal Phenomenon - the Case of Serbia}

Psychoactive substance addiction presents a challenging public health issue worldwide particularly targeting vulnerable adolescent population (Babor et al., 2007). The illegal market turnover of the controlled substances is very difficult to trace and intervene timely among the young in the early stage of illness (Inciardi et al., 2007). Contrary to this one, legally regulated pharmaceuticals pose

OPEN ACCESS

Edited by:

Wil Toenders,

ToendersdeGroot BV, Netherlands

Reviewed by:

J. M. Ad Sitsen,

ClinPharMed, Netherlands

${ }^{*}$ Correspondence: Mihajlo (Michael) Jakovljevic, sidartagothama@gmail.com

Specialty section:

This article was submitted to

Pharmaceutical Medicine and

Outcomes Research,

a section of the journal

Frontiers in Pharmacology

Received: 29 July 2015

Accepted: 25 August 2015

Published: 15 September 2015

Citation:

Jakovljevic M, Lazarevic M, Jurisevic $M$ and Jovanovic MR (2015) When cure becomes an illness-abuse of addictive prescription medicines.

Front. Pharmacol. 6:193.

doi: 10.3389/fphar.2015.00193 another dangerous threat that is more accessible to the authorities. In order to combat substance dependence the national strategies should specially emphasize prescription medicines with proven potential of abuse and addiction (Compton and Volkow, 2006).

Serbia as the largest Western Balkans market and a typical Eastern European transitional health system might serve as an appropriate example of medicines abuse in the EU borderlands (Jakovljevic, 2013). The results of local research in 2008, showed that $15.1 \%$ of first grade high school students, at least once had used, some psychoactive substance (excluding nicotine and alcohol), while $7.6 \%$ of them used sedatives, which was the most common [European School Survey Project on Alcohol and Other Drugs (ESSPAD), 2008]. The national survey on life styles of citizens in Serbia in 2014 about substance use and gambling addiction reported that in the past 12 months $22.4 \%$ of the respondents used sedatives, anxiolytics or hypnotics drugs (13.9\% of males and $30.9 \%$ of females) and in the last 30 days $14.6 \%$ of respondents ( $8 \%$ of males and $21.2 \%$ of females) used these drugs with higher preponderance among older population. In the last 12 months $5.1 \%$ of the respondents used opioids for pain treatment ( $4.1 \%$ of males and $6.1 \%$ of females) and in the last 30 days $2.2 \%$ of respondents (1.6\% of males and $2.8 \%$ of females) used these drugs. A large number of respondents said that they had purchased these drugs in the pharmacies prescribed by their physicians $-85.3 \%$ of the population $18-64$ years of age used hypnotics and sedatives, and $70.3 \%$ of the population used opioid drugs (Kilibarda et al., 2014).

Various studies have shown that drug addiction disorders are related to personality disorders, anxiety disorders and a considerably higher suicide rate (Regier et al., 1990). Further consequences of drug addiction are: education (Yamada et al., 1993) and employment underachievement, reduced work productivity, poor health, higher rates of human immunodeficiency virus (HIV) and hepatitis B and C infections (Jakovljevic et al., 2013a), social dysfunction, higher rate of violence and incarceration among that population, poverty, homelessness, a lower probability of recovery, poor treatment outcomes, and poor quality of life. The treatment system for substance use disorders is accompanied by high public and private expenses (Jovanovic and Jakovljevic, 2011). 


\section{Pharmaceutical Market in a Late-stage Transitional Health Reform Setting}

The national health care system of Serbia is financed by mandatory tax contributions by employers and employees alike to the National Health Insurance Fund. The health care system of Serbia similar to Eastern European countries, have undergone profound transitional reforms with different degrees of success in different areas of medical service provision and outcomes (Jakovljevic et al., 2011). Over the last 20 years, pharmaceutical and total health care expenditures were growing more rapidly than gross domestic product (GDP) in many world regions (Getzen, 1990). The Serbian pharmaceutical market was characterized by a large growth in public expenditure on pharmaceuticals (from $€ 339,279,304$ in 2004 to $€ 794,560,045$ in 2013). The Sudden expansion in the market led to the increase of Serbia's public debt and accumulated debt of wholesalers toward brand industry in the entire region (Jakovljevic et al., 2015a). These developments eventually led to the crisis of financial sustainability and serious market shortages of even some fundamental medicines (Jakovljevic, 2014). Primary health care facilities were intended to act as "gate keepers" of the health care system. Their success in this role to contain "supplier induced demand" in clinical medicine was frequently examined in public opinion (Vuković et al., 2015). Preventive public health measures and early screening procedures remain an ongoing weakness of the most regional health systems and Serbia is no exception. In the long run, the evolution of prosperity diseases and accelerated population aging are most likely to persist as the core challenges in the broader Balkans region (Jakovljevic and Laaser, 2015).

\section{Signs of Addictive Prescription Medicines Abuse}

Published trials from late 1990s provide clear-cut evidence of upward trend in the consumption of psychiatric drugs in Serbia and Montenegro (Miljkovic and Djukic, 2000). The Utilization of all drugs acting on the nervous system (inclusive of psychiatric drugs) grew from $28.9 \mathrm{DDD} / 1000$ inhabitants/day in 1996 to $69.1 \mathrm{DDD} / 1000$ inhabitants/day in 2004. Among the causes of this growth, the most frequently cited are increased incidence of psychiatric disorders, post-war syndromes that followed the Yugoslav civil wars and higher accessibility of prescription medicines at the time (Divac et al., 2004).

Contemporary policy, since the early 2000s, is that majority of approved and marketed potentially addictive medicines are assigned to the positive list and completely reimbursed within the basic health insurance premium. Extensive annual reports on prescription and dispensing of drugs in terms of defined daily doses per 1000 inhabitants per day (DDD/1000 inhabitants/day) are released at regular times by the National Medicines and Medicinal Devices Agency of Serbia (ALIMS; Agencija za lekove i medicinska sredstva Srbije, 2013). In Table 1 we can remark DDDs and value base turnover of six selected
ATC (Anatomical Therapeutic Chemical Classification System) ${ }^{1}$ code groups of such medicines: anesthetics, opioids, anxiolytics, hypnotics and sedatives, psychostimulants, agents used for ADHD (Attention deficit hyperactivity disorder), nootropics and drugs used in addictive disorders. The results are presented using WHO recommended ATC/DDD methodology (Sjöqvist and Birkett, 2003). The consumption of psychostimulants, agents used for ADHD and nootropics grew tremendously (from $0.35 \mathrm{DDD} / 1000$ inhabitants/day in 2004 to $6.61 \mathrm{DDD} / 1000$ inhabitants/day in 2013). The consumption of hypnotics and sedatives has almost doubled (from 2.47 DDD/1000 inhabitants/day in 2004 to $4.02 \mathrm{DDD} / 10000$ inhabitants/day in 2013) primarily due to benzodiazepine derivatives. A promising sign is the rise of prescription of drugs used to treat addictive disorders (from $0.31 \mathrm{DDD} / 1000$ inhabitants/day in 2004 to 1.50 DDD/1000 inhabitants/day in 2013). Among these ATC code groups, the most frequent consumption was recorded in the case of agents that are indicated in opioid dependence.

Pharmaceutical spending related to all of the aforementioned groups of medicines has strongly increased during the same time span. The most significant budget impact was attributed to the anxiolytics consumption in $2013(€ 15,091,052)$ in comparison to $€ 9,450,094$ back in 2004 . This finding is wholly justified by previous findings on heavily increased anxiety levels among resident addicts in the former Yugoslav region compared to traditional EU-15 market economies (Jakovljevic et al., 2013b). Psychostimulants related costs were multiplied 10-fold ( $€ 287,766$ in 2004 to $€ 3,138,433$ in 2013). Over the same time horizon following aforementioned growth pattern in DDD terms, the costs of pharmaceuticals used to treat substance dependence increased heavily as well (from $€ 236,734$ in 2004 to $€ 1,900,777$ in 2013).

\section{Conclusive Remarks}

Although the situation appears to implicate an extensive public debate in this region, we should be aware of the fact that a large portion of reported consumption is clinically justified with basic mental illness. It would be highly difficult and demanding rigorous methodological approach to exactly identify the proportion of overutilization of these drugs that is attributed to abuse and addiction. Nevertheless, vast net quantity gains in consumed addictive medications in definite ATC groups by far surpass extended burden of associated psychiatric morbidity in recent years (Ristic-Ignjatovic et al., 2013). Therefore, this insight gives grounds for serious concerns about widespread patient abuse of addictive medicines in this country and beyond.

The abuse of potentially addictive medicines correlates with clinicians' decision making principles (Bendtsen et al., 1999) and locally prevailing psychiatrist practice (Jakovljevic et al., 2015b). Citizens' possibility to purchase these medicines without medical prescription has been proven as another major driver of abuse potential (Lessenger and Feinberg, 2008). It is reported that up to $4.4 \%$ adults consuming sedatives and hypnotics

\footnotetext{
${ }^{1}$ Anatomical Therapeutic Chemical Classification System. Available online at: http://www.whocc.no/atc_ddd_index/.
} 
TABLE 1 | National level dispensing (Defined Daily Doses per 1000 population/day) and consumption (€) of major potentially addictive medicines and those used to treat substance addiction in 2004 and 2013 in Serbia.

\begin{tabular}{|c|c|c|c|c|}
\hline ATC code group & $\begin{array}{l}\text { Reimbursed value } \\
\text { of dispensed } \\
\text { medicines in } 2004\end{array}$ & $\begin{array}{l}\text { Reimbursed value } \\
\text { of dispensed } \\
\text { medicines in } 2013\end{array}$ & $\begin{array}{c}\text { DDD per } 1000 \\
\text { inhabitants/hospital } \\
\text { day in } 2004\end{array}$ & $\begin{array}{c}\text { DDD per } 1000 \\
\text { inhabitants/hospital } \\
\text { day in } 2013\end{array}$ \\
\hline \multicolumn{5}{|l|}{ POTENTIALLY ADDICTIVE MEDICINES } \\
\hline N01A Anesthetics, General & $€ 1,283,128$ & $€ 4,072,544$ & $\mathrm{~N} / \mathrm{A}$ & N/A \\
\hline N01AF Barbiturates, plain & $€ 21,465$ & $€ 101,842^{2009}$ & $\mathrm{~N} / \mathrm{A}$ & N/A \\
\hline N02A Opioids & $€ 1,472,459$ & $€ 2,499,864$ & 0.84 & 0.52 \\
\hline N02AA Natural opium alkaloids & $€ 197,341$ & $€ 611,410$ & 0.04 & 0.08 \\
\hline N02AB Phenylpiperidine derivatives & $€ 272,205$ & $€ 1,341,574$ & 0.03 & 0.11 \\
\hline N02AD Benzomorphan derivatives & $€ 818$ & $€ 506^{2006}$ & 0.00 & N/A \\
\hline N02AX Other opioids (mostly tramadol based preparations) & $€ 1,002,095$ & $€ 546,880$ & 0.77 & 0.33 \\
\hline N03AA Barbiturates and derivatives & $€ 427,676$ & $€ 263,570$ & 2.9 & 2.03 \\
\hline N03AE Benzodiazepine derivatives & $€ 291,568$ & $€ 1,288,405$ & 0.63 & 2.48 \\
\hline N05AH Diazepines, oxazepines, thiazepines, and oxepines & $€ 1,529,558$ & $€ 4,925,668$ & 0.37 & 1.53 \\
\hline N05B Anxiolytics & $€ 9,450,094$ & $€ 15,091,052$ & 106.95 & 79.81 \\
\hline N05BA Benzodiazepine derivatives & $€ 9,448,412$ & $€ 15,091,052$ & 106.95 & 79.81 \\
\hline N05C Hypnotics and sedatives & $€ 1,197,390$ & $€ 2,232,897$ & 2.47 & 4.02 \\
\hline N05CD Benzodiazepine derivatives & $€ 1,197,390$ & $€ 1,459,522$ & 2.47 & 1.98 \\
\hline N05CF Benzodiazepine related drugs & $€ 0$ & $€ 773,375$ & 0.00 & 2.03 \\
\hline N06B Psychostimulants, agents used for ADHD and nootropics & $€ 287,766$ & $€ 3,138,433$ & 0.35 & 6.61 \\
\hline R01AA Sympathomimetics, plain (mostly ephedrine based preparations) & $€ 1,676,145$ & $€ 4,328,551$ & 132.14 & 14.83 \\
\hline R05DA Opium alkaloids and derivatives & $€ 74,118$ & $€ 28,649$ & 0.05 & 0.03 \\
\hline R06AB Substituted alkylamines (mostly pheniramine derivatives) & $€ 492,461$ & $€ 2,764,304$ & 0.56 & 0.08 \\
\hline \multicolumn{5}{|l|}{ MEDICINES USED TO TREAT SUBSTANCE ADDICTION } \\
\hline N07B Drugs used in addictive disorders & $€ 236,734$ & $€ 1,900,777$ & 0.31 & 1.50 \\
\hline N07BA Drugs used in nicotine dependence & $€ 138,139$ & $€ 407,718$ & 0.03 & 0.10 \\
\hline N07BB Drugs used in alcohol dependence & $€ 35,123$ & $€ 206,726$ & 0.19 & 0.53 \\
\hline N07BC Drugs used in opioid dependence & $€ 63,472$ & $€ 1,286,332$ & 0.09 & 0.88 \\
\hline
\end{tabular}

on a daily base. This amounts to an overall population of 182,000-234,000 regular users of sedatives and hypnotics among population aged from 18 to 64 . This phenomena might have a difficult and concerning extent among the small Balkan nations (Divac et al., 2009). Similar life styles reported in public health surveys across EU might indicate that the abuse of potentially addictive medicines could have the far reaching consequences in the European continent (United Nations Office on Drugs and Crime, 2010). There are several possible tactics to cope with this challenge for overprescribing pattern and irrational consumption of these medicines could be partially controlled by paying more attention to potentially susceptible patients during regular check-ups (Khan et al., 2015). Strengthening of the regulatory framework in marketing approval and reimbursement could impose more strict legal control to the over-the-counter sales of this medicines. Software based good clinical practice guidelines have already confirmed strong benefits in terms of patient outcomes and cost savings in a local clinical setting (Jakovljevic et al., 2014). Health education program development targeted for addictive patients' needs (Wolde et al., 2008) and those suffering from other mental illnesses at the risk of developing substance dependence, could improve patient support and counseling (Hashemi and Hashemi, 2015). The experience of the successful implementation of alternative and complementary medicine methods attained in many countries, might serve as an additional example of exit strategies probably to bring relief to this vulnerable patient population.

\section{Funding}

The underlying studies providing evidence for this contribution where funded out of The Ministry of Education Science and Technological Development of the Republic of Serbia Grant OI 175014. Publication of results was not contingent to Ministry's censorship or approval. 


\section{References}

Agencija za lekove i medicinska sredstva Srbije. (2013). Promet $i$ Potrosnja Gotovih Lekovaza Humanu u potrebu u Republici Srbijiu 2012. Godini. Beograd: Helicon Publishing. Available online at: http://www.alims.gov.rs/ciril/files/2014/09/PROMET_javnost-2012.pdf

Babor, T. F., McRee, B. G., Kassebaum, P. A., Grimaldi, P. L., Ahmed, K., and Bray, J. (2007). Screening, Brief Intervention, and Referral to Treatment (SBIRT) toward a public health approach to the management of substance abuse. Subst. Abus. 28, 7-30. doi: 10.1300/J465v28n03_03

Bendtsen, P., Hensing, G., McKenzie, L., and Stridsman, A. K. (1999). Prescribing benzodiazepines a critical incident study of a physician dilemma. Soc. Sci. Med. 49, 459-467. doi: 10.1016/S0277-9536(99)00133-1

Compton, W. M., and Volkow, N. D. (2006). Abuse of prescription drugs and the risk of addiction. Drug Alcohol Depend. 83, S4-S7. doi: 10.1016/j.drugalcdep.2005.10.020

Divac, N., Jašović, M., Djukic, L., Vujnovic, M., Babic, D., Bajcetic, M., et al. (2004). Benzodiazepines utilization and self-medication as correlates of stress in the population of Serbia. Pharmacoepidemiol. Drug Saf. 13, 315-322. doi: $10.1002 /$ pds. 940

Divac, N., Todorovic, Z., Stojanovic, R., Nesic, Z., Jasovic-Gasic, M., LecicTosevski, D., et al. (2009). Utilization of psychiatric drugs in Serbia. Vojnosanit. Pregl. 66, 233-237. doi: 10.2298/VSP0903233D

European School Survey Project on Alcohol and Other Drugs (ESSPAD). (2008). EvropskoistraŽivanje o upotrebialkoholaidrugihdrogameğumladima u Srbiji, 2008. Belgrade: Ministry of Health of the Republic of Serbia, Institute of Public Health of Serbia, "DrMilanJovanovic-Batut."

Getzen, T. E. (1990). Macro forecasting of national health expenditures. $A d v$. Health Econ. Health Serv. Res. 11, 27.

Hashemi, S., and Hashemi, S. A. R. A. (2015). Effectiveness of group cognitive behavioral intervention to increase perceived social support in patients with substance abuse (a treatment model in prevention of substance abuse). Eur. Psychiatry 30, 1101. doi: 10.1016/s0924-9338(15)30869-5

Inciardi, J. A., Surratt, H. L., Kurtz, S. P., and Cicero, T. J. (2007). Mechanisms of prescription drug diversion among drug-involved club-and street-based populations. Pain Med. 8, 171-183. doi: 10.1111/j.1526-4637.2006.00255.x

Jakovljevic, M. B. (2013). Resource allocation strategies in Southeastern European health policy. Eur. J. Health Econ. 14, 153-159. doi: 10.1007/s10198-012-0439-y

Jakovljevic, M. B. (2014). Health Expenditure Dynamics in Serbia 1995-2012, Hospital Pharmacology. Int. Multidiscipli. J. 1, 180-183.

Jakovljevic, M., and Laaser, U. (2015). Population aging from 1950 to 2010 in seventeen transitional countries in the wider region of South Eastern Europe (Original research). SEEJPH. doi: 10.12908/SEEJPH-2014-42 [Epub ahead of print].

Jakovljevic, M., Djordjevic, N., Jurisevic, M., and Jankovic, S. (2015a). Evolution of Serbian pharmaceutical market alongside socioeconomic transition. Expert Rev. Pharmacoecon. Outcomes Res. 15, 521-530. doi: 10.1586/14737167.2015.1003044

Jakovljevic, M., Jovanovic, M., Lazic, Z., Jakovljevic, V., Djukic, A., Velickovic, R., et al. (2011). Current efforts and proposals to reduce healthcare costs in Serbia. Ser. J. Exp. Clin. Res. 12, 161-310. doi: 10.5937/sjecr1104161J

Jakovljevic, M., Jovanovic, M., Rancic, N., Vyssoki, B., and Djordjevic, N. (2014). LAT software induced savings on medical costs of alcohol addicts' care results from a matched-pairs case-control study. PLOS ONE 9:e111931. doi: 10.1371/journal.pone.0111931

Jakovljevic, M., Mijailovic, Z., Jovicic, B. P., Canovic, P., Gajovic, O., Jovanovic, M., et al. (2013a). Assessment of viral genotype impact to the cost-effectiveness and overall costs of care for Peg-interferon- $2 \alpha+$ ribavirine treated chronic hepatitis C patients. Hepat. Mon. 13:e6750. doi: 10.5812/hepatmon.6750
Jakovljevic, M., Riegler, A., Jovanovic, M., Djordjevic, N., Patek, K., Lesch, O., et al. (2013b). Serbian and Austrian alcohol-dependent patients: a comparison of two samples regarding therapeutically relevant clinical features. Alcohol Alcohol. 48, 505-508. doi: 10.1093/alcalc/agt011

Jakovljevic, M., Vukovic, M., Chia-Ching, C., Antunovic, M., Dragojevic- Simic, V., Velickovic-Radovanovic, R., et al. (2015b). Do health reforms impact cost consciousness of Health care professionals? Results from a nation-wide survey in the Balkans. Balkan Med. J. doi: 10.5152/balkanmedj.2015.15869 [Epub ahead of print].

Jovanovic, M., and Jakovljevic, M. (2011). Inpatient detoxification procedure and facilities: financing considerations from an Eastern European perspective. Alcohol Alcohol. 46, 364-365. doi: 10.1093/alcalc/agr010

Khan, M., Saeed, R., Sujjat, J., Mukhtar, Z., and Naiz, S. (2015). Preventive strategies for medically induced drug addiction. Eur. Psychiatry 30, 1070. doi: 10.1016/s0924-9338(15)30844-0

Kilibarda, B., Kilibarda, B., Mravcik, V., Sieroslawski, J., Rakic, J. G., and Martens, M. S. (2014). National Survey on Life Styles of Citizen in Serbia 2014:Key Findings on Substance use and Gambling. Beograd: Institute of Public Health of Serbia.

Lessenger, J. E., and Feinberg, S. D. (2008). Abuse of prescription and over-the-counter medications. J. Am. Board Fam. Med. 21, 45-54. doi: 10.3122/jabfm.2008.01.070071

Miljkovic, M., and Djukic, L. J. (2000). Analysis of drug utilization in Serbia during the years 1996 and 1997. Pharmacoepidemiol. Drug Saf. 9, 59-64. doi: 10.1002/(SICI)1099-1557(200001/02)9:1\%3C59

Regier, D. A., Farmer, M. E., Rae, D. S., Locke, B. Z., Keith, S. J., Judd, L. L., et al. (1990). Comorbidity of mental disorders with alcohol and other drug abuse: results from the Epidemiologic Catchment Area (ECA) study. JAMA 264, 2511-2518. doi: 10.1001/jama.1990.03450190043026

Ristic-Ignjatovic, D., Hinic, D., Jakovljevic, M., Fountoulakis, K., Siapera, M., and Rancic, N. (2013). A ten-year study of depressive symptoms in Serbian medical students. Acta Clin. Croat. 52, 157-164.

Sjöqvist, F., and Birkett, D. (2003). Drug Utilization. Introduction to Drug Utilization Research. Geneva: WHO.

United Nations Office on Drugs and Crime. (2010). World Drug Report 2010. New York, NY: United Nations Publications.

Vuković, M., Gvozdenović, B. S., Rankoviæ, M., McCormick, B. P., Vuković, D. D., Gvozdenović, B. D., et al. (2015). Can didactic continuing education improve clinical decision making and reduce cost of quality? Evidence from a case study. J. Contin. Educ. Health Prof. 35, 109-118. doi: 10.1002/chp. 21272

Wolde, G., Dijkstra, A., Empelen, P., Neven, A., and Zitman, F. (2008). Psychologial determinants of the intentions to educate patients about benzodiazepines. Pharm. World Sci. 30, 336-342. doi: 10.1007/s11096-0079183-2

Yamada, T., Kendix, M., and Yamada, T. (1993). The Impact of Alcohol Consumption and Marijuana use on High School Graduation (No. w4497). New York, NY: National Bureau of Economic Research.

Conflict of Interest Statement: The authors declare that the research was conducted in the absence of any commercial or financial relationships that could be construed as a potential conflict of interest.

Copyright (c) 2015 Jakovljevic, Lazarevic, Jurisevic and Jovanovic. This is an openaccess article distributed under the terms of the Creative Commons Attribution License (CC BY). The use, distribution or reproduction in other forums is permitted, provided the original author(s) or licensor are credited and that the original publication in this journal is cited, in accordance with accepted academic practice. No use, distribution or reproduction is permitted which does not comply with these terms. 